\title{
Desperate therapies and the amazing race for antimicrobial alternatives
}

\author{
A Mark Joffe MD FRCP(C)
}

It is not difficult to make microbes resistant to penicillin in the laboratory by exposing them to concentrations not sufficient to kill them.

- Sir Alexander Fleming, Nobel Prize Acceptance Speech, 1945

Infectious diseases remain a leading cause of death worldwide. Despite this fact, as well as the increasing recognition that microbial resistance is emerging as a serious threat to human health, antimicrobial research and development are declining. The current situation has evolved through a complex interaction of scientific, economic and regulatory forces. New approaches are needed. If therapies are unavailable or failing, we have only two options: we can prevent infections or we can develop new strategies to deal with them.

Developing novel strategies for confronting antibiotic resistance is one of the strategic research priorities of the Canadian Institutes of Health Research (CIHR) Institute of Infection and Immunity. To this end, an interactive workshop was held in Vancouver, British Columbia, from March 10 to 11,2005 , to consider novel alternatives to antibiotics. Three themes emerged from this workshop as research priorities: modulation of host immunity, phage therapy and physical systems/biomaterials. Other areas of potential interest were probiotics, bioprospecting and novel target identification, as well as rapid and point-of-care diagnostics.

This initial CIHR workshop was geared primarily to those with large research portfolios. In order to take some of these ideas to the bedside and the clinical microbiology laboratory, the CIHR cosponsored a second workshop at the 2006 Annual Meeting of the Association of Medical Microbiology and Infectious Disease Canada (AMMI Canada) and the Canadian Association for Clinical Microbiology and Infectious Diseases (CACMID). This workshop was entitled "Desperate Therapies and the Amazing Race for Antimicrobial Alternatives" and was held in Victoria, British Columbia, on March 18, 2006. The workshop generated tremendous interest and was attended by nearly 400 delegates and interested participants. The following four articles in this issue of The Canadian Journal of Infectious Diseases 89 Medical Microbiology were derived from four of the plenary talks delivered during this workshop.

Also featured during this workshop was a talk by Dr JM Hutchinson from Memorial University, entitled, "Population antimicrobial use and resistance: How do we fare in Canada?" This discussion highlighted the gross differences in antimicrobial prescribing patterns across our vast land. These astonishing differences are unlikely to reflect dissimilarity among Canadians and must therefore reflect other differences, possibly formulary structure, marketing, influence of opinion leaders or potentially others.

The day ended with a stirring debate in which Dr E Blondel Hill argued that antibiotic use can be controlled, while Dr J Conly countered that controlling antimicrobial use is not possible. Passionate arguments were delivered with conviction by both discussants. While Dr Conly offered a compelling case, the audience ultimately thought there still remains opportunity to control at least some aspects of antimicrobial use.

The workshop organizers are grateful to the CIHR for cosponsoring this very successful workshop together with AMMI Canada and CACMID.

Infection Prevention and Hospital Epidemiology, Division of Infectious Diseases, Royal Alexandra Hospital, Edmonton, Alberta

Correspondence: Dr A Mark Joffe, Infection Prevention and Hospital Epidemiology, Division of Infectious Diseases, 303-CSC Royal

Alexandra Hospital, 10240 Kingsway, Edmonton, Alberta T5H 3V9. Telephone 780-735-5778, fax 780-735-5681,

e-mailmjoffe@ualberta.ca 


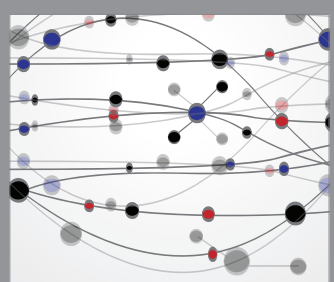

The Scientific World Journal
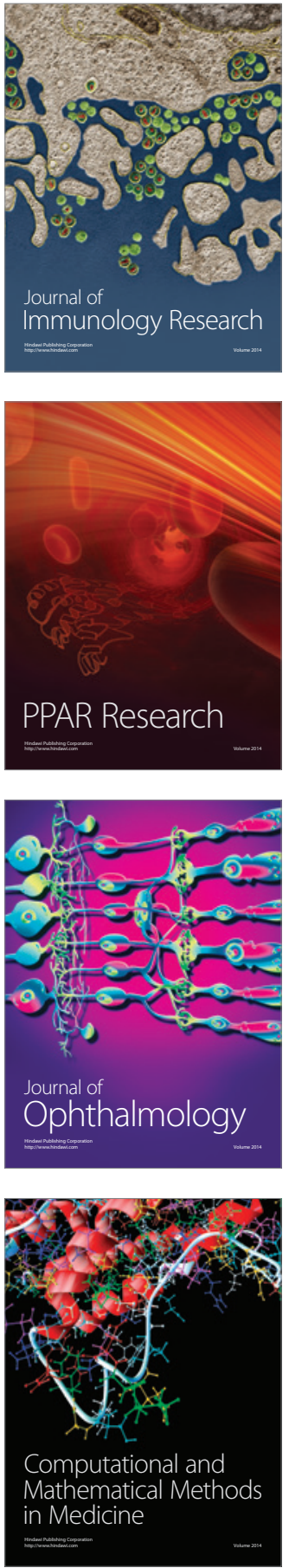

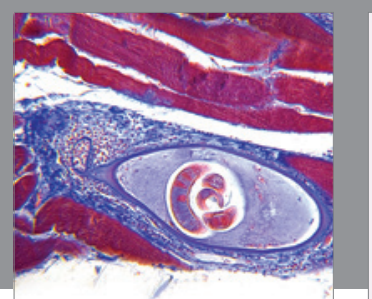

Gastroenterology Research and Practice

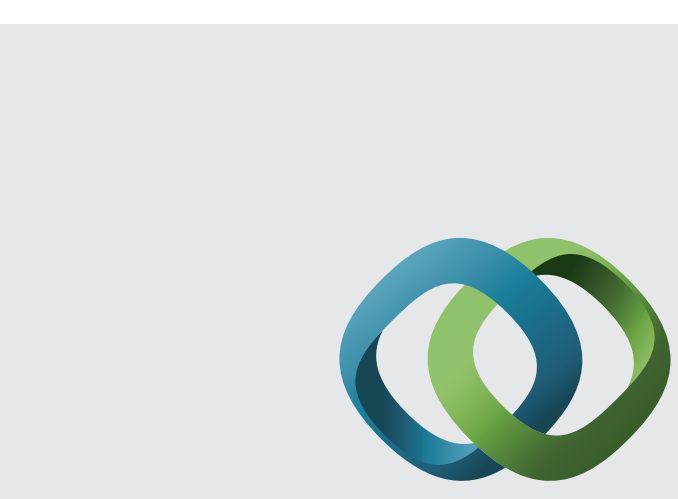

\section{Hindawi}

Submit your manuscripts at

http://www.hindawi.com
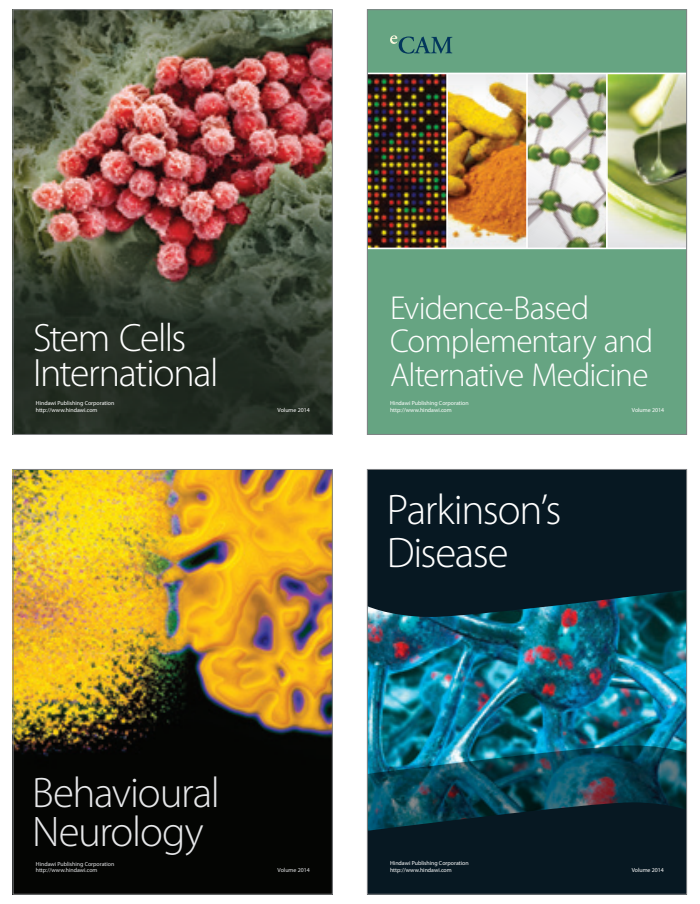
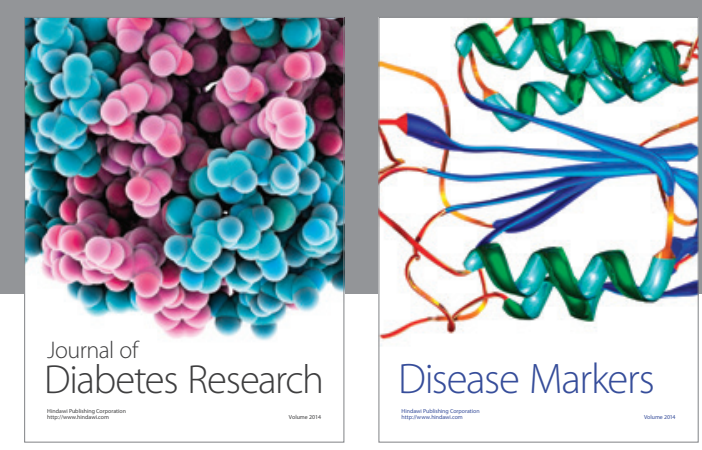

Disease Markers
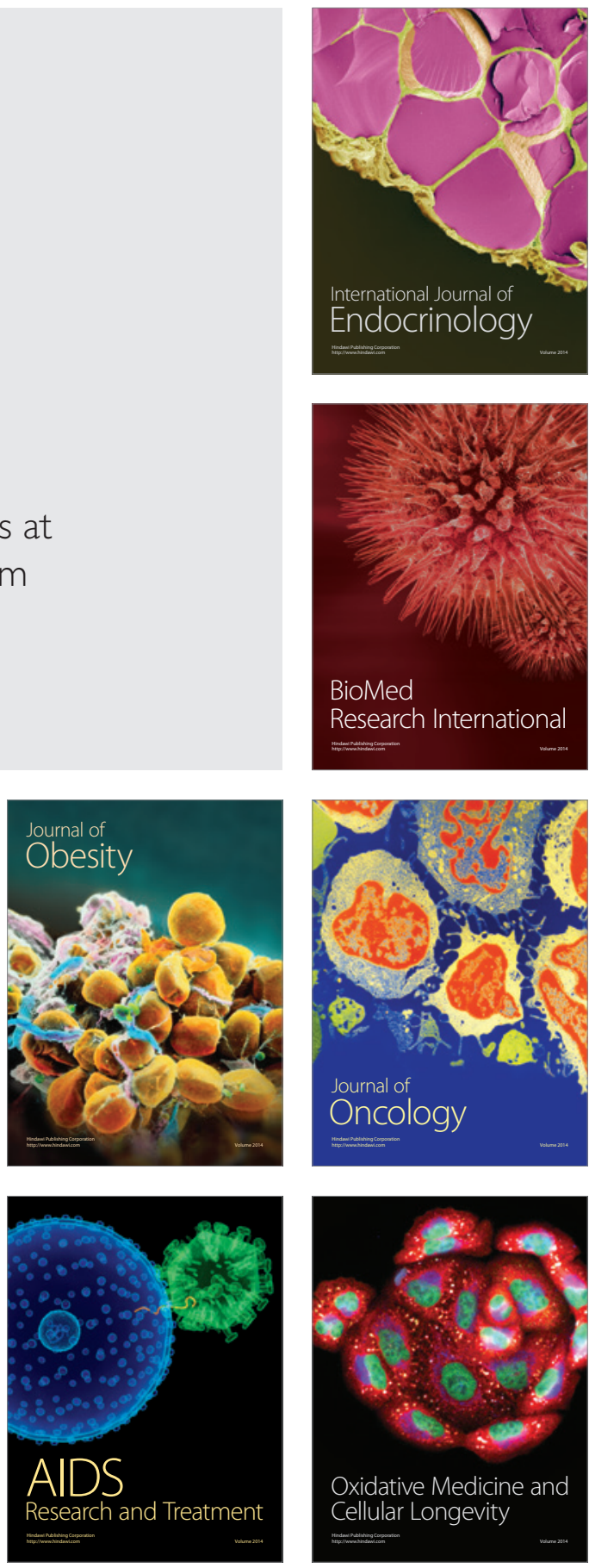